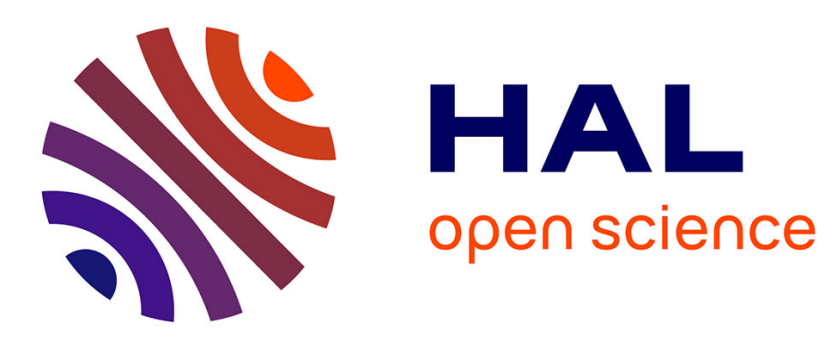

\title{
Effect of stress ratio on VHCF behavior for a compressor blade titanium alloy
}

Zhi Yong Huang, Han Qing Liu, Hao Min Wang, Danièle Wagner, Muhammad Kashif Khan, Qing Yuan Wang

\section{- To cite this version:}

Zhi Yong Huang, Han Qing Liu, Hao Min Wang, Danièle Wagner, Muhammad Kashif Khan, et al.. Effect of stress ratio on VHCF behavior for a compressor blade titanium alloy. International Journal of Fatigue, 2016, 93, pp.232 - 237. 10.1016/j.ijfatigue.2016.05.004 hal-01687203

\section{HAL Id: hal-01687203 https://hal.parisnanterre.fr/hal-01687203}

Submitted on 18 Jan 2018

HAL is a multi-disciplinary open access archive for the deposit and dissemination of scientific research documents, whether they are published or not. The documents may come from teaching and research institutions in France or abroad, or from public or private research centers.
L'archive ouverte pluridisciplinaire $\mathbf{H A L}$, est destinée au dépôt et à la diffusion de documents scientifiques de niveau recherche, publiés ou non, émanant des établissements d'enseignement et de recherche français ou étrangers, des laboratoires publics ou privés. 


\title{
Effect of stress ratio on VHCF behavior for a compressor blade titanium alloy
}

\author{
Zhi Yong Huang ${ }^{\mathrm{a}, *}$, Han Qing Liu ${ }^{\mathrm{a}}$, Hao Min Wang ${ }^{\mathrm{a}}$, Danièle Wagner ${ }^{\mathrm{b}}$, Muhammad Kashif Khan ${ }^{\mathrm{c}}$, \\ Qing Yuan Wang ${ }^{\mathrm{a}}$ \\ a Sichuan University, School of Aeronautics and Astronautics, No. 29 Jiuyanqiao Wangjiang Road, Chengdu 610064, China \\ ${ }^{\mathrm{b}}$ Université Paris Ouest Nanterre La Défense, France \\ ${ }^{c}$ Coventry University, School of Mechanical, Aerospace and Automotive Engineering, Coventry CV1 5FB, UK
}

Keywords:

Titanium alloy

High cycle fatigue

Very high cycle fatigue

Fatigue failure

Mean stress

\begin{abstract}
A B S T R A C T
Effect of stress ratio on fatigue properties of a titanium alloy (TC-17) in the high cycle fatigue (HCF) and very high cycle fatigue (VHCF) were investigated by electromagnetic and ultrasonic fatigue testing. The $S-N$ curves at $R=-1,0.1,0.5$ and 0.7 at $110 \mathrm{~Hz}$ and $20 \mathrm{kHz}$ were obtained and discussed. The effects of frequency on fatigue strength was also investigated. It was concluded that the fatigue strength with $50 \%$ fatigue failure probability at $R=0.1,0.5$ and 0.7 is lower to the Goodman line and shows a bilinear decreasing trend. Cleavage fracture of primary grains in the surface and interior initiation zone were observed. The formation of the facets induced by the basal or prismatic slips of the H.C.P grains decreased the fatigue strength with variation in mean stress.
\end{abstract}

\section{Introduction}

Compressor blades of aero engines are the failure prone components owning to high inertial centrifugal forces and airflow which excites the blades with high frequency vibration. The fatigue failure in the aero engine blades is found in the very high cycle fatigue (VHCF) regime [1]. Titanium alloys are frequently used in high strength and low weight aeronautical applications, such as beams, joints and bulkheads to withstand the aero dynamic loads. The service life requirement of these components and high load frequency usually lead to the VHCF failure. The fatigue strength of the components can be determined from the responses of material and structures. The fatigue design is obtained from "Haigh" or "Goodman" diagrams which are plotted between stress amplitude and mean stress for a constant life [2].

The number of cycles are often within $10^{7}$ assuming a "fatigue limit" afterwards. The test results at stress ratio $R=-1$ and greater than -1 can be obtained by hydraulic and electromagnetic fatigue machine with different mean stresses and frequencies. However, the longer duration and high loading frequency may show the fatigue failure beyond $10^{7}$ cycles. In very high cycle fatigue up to $10^{9}$ $10^{10}$ cycles, the $S-N$ curves show a continuous or step wise

\footnotetext{
* Corresponding author.

E-mail address: huangzy@scu.edu.cn (Z.Y. Huang).
}

decreasing pattern [3]. The crack initiation location shifts from surface to interior of the specimen beyond $10^{7}$ cycles.

With the application of piezoelectric technology [4], the VHCF tests process can be achieving high frequencies up to $20-30 \mathrm{kHz}$ and the results can be obtained very quickly. Many kinds of ultrasonic fatigue machines have now been developed capable of testing specimen like tension-compression or tension-tension reported by Bathias et al. [5] and Stanzel [6], torsion by Bathias et al. [7] and torsion with mean stress by Mayer [8], bending by Xue et al. [9] and fretting by Filgueiras et al. [10]. The machines have been used in investigation of the effect of service environment, like elevated temperature [11] and corrosion [12] on VHCF properties have also been studied. The microstructure features of the metallic materials such as inclusion, grain size and crystal orientation $[11,13]$ were studied for fatigue crack initiation in VHCF regime.

However, very few efforts have been made to observe the effect of mean stress on the fatigue properties of titanium alloy up to VHCF. The absence of test data at certain stress ratios induces the diagram constructed by a straight line from the fatigue strength at $R=-1$ to the ultimate tensile strength (UTS). The effects of frequency on VHCF behavior with different mean stresses (i.e. $R>0$ ) need yet to be understood for the titanium alloys. In the article, the crack initiation mechanism and fatigue performance with effect of different mean stresses and frequencies on TC-17 titanium alloy have been discussed. It was found the fatigue strength at different mean stresses 
is lower to the Goodman line. The fracture surface of the material showed variation with mean stress used in fatigue loading. The basal or prismatic slips of the H.C.P grains decreased the fatigue strength with variation in the mean stress.

\section{Material and experiments}

Titanium alloy TC-17 (Chinese standard) contains about 5\% Al, $2 \% \mathrm{Sn}$ and $2 \% \mathrm{Zr}$. The actual composition of the alloy is shown in Table 1 with weight percentage. The alloy contains about $40 \%$ volume fraction of primary $\alpha$ phase and 60\% lamellar structure with secondary $\alpha$ plates embedded in the $\beta$ matrix as shown in Fig. 1. The diameter of the primary $\alpha$ grains $\left(\alpha_{p}\right)$ is about $2-6 \mu \mathrm{m}$.

The fatigue tests were implemented by the electromagnetic fatigue test and piezoelectric fatigue test machines at $110 \mathrm{~Hz}$ and $20 \mathrm{kHz}$ respectively. Fatigue specimens were made with hourglass shape and designed to resonate at $20 \mathrm{kHz}$ frequency in longitudinal direction. The test specimen for $110 \mathrm{~Hz}$ electromagnetic fatigue machine was designed in a shape similar to the ultrasonic test specimens. The minimum diameter in both type of testing was kept to $3 \mathrm{~mm}$ to avoid the effect of dimension in the two kinds of test machine.

Surface analysis device (Leica DCM 8) was used to measure the surface quality of the specimen. The arithmetical mean deviation of the profile ( $\mathrm{Ra}$ ) was about $0.817 \mu \mathrm{m}$. The Vickers hardness is measured along the diameter in the center section of the specimen and the average hardness value is about $370 \mathrm{HV}$.

The mechanical ultrasonic vibration load was generated by a convertor composed by six piezoelectric ceramic components excited by the power amplifier with $20 \mathrm{kHz}$ sine wave signal. The specimen was excited to vibrate with high frequency normally working in the full reversed condition $(R=-1)$. In order to obtain the mean stress for the tests, dynamic vibration loading was combined with static tension by installing the piezoelectric fatigue system on the static electric tension machine (SHIMADZU-20 kN) [3]. The ultrasonic fatigue system was suspended on the crosshead of the tensile machine and the whole system was controlled by the computer with special data acquisition system through several numerical interfaces. The grips were designed only for adapting the piezoelectric fatigue vibration system. The horns connected to the ultrasonic specimen were necessary to transmit and amplify the stress waves. The contact position for the grips and horns were set as a vibration node characterized by a theoretical constant zero amplitude.

In order to test the effect of frequency, the ultrasonic $(20 \mathrm{kHz})$ fatigue machine and electromagnetic fatigue test machine $(110 \mathrm{~Hz})$ were used at $R=-1,0.1,0.5,0.7$ at room temperature (RT). The infrared camera was also used to measure the temperature increment of the specimens' surface caused by self - heating of specimen during the high frequency fatigue tests with mean stress. The surfaces of the specimens were painted by a black high temperature resistance painter to reduce the temperature measurement error in the testing.

\section{Test results}

\section{1. $S-N$ curves}

Fig. 2 shows the response of the material at $110 \mathrm{~Hz}$ and $20 \mathrm{kHz}$ frequency. The different forms of points in figure were used to

Table 1

TC-17 chemical composition (wt.\%).

\begin{tabular}{llllllllll}
\hline $\mathrm{Al}$ & $\mathrm{Sn}$ & $\mathrm{Mo}$ & $\mathrm{Cr}$ & $\mathrm{Zr}$ & $\mathrm{Fe}$ & $\mathrm{C}$ & $\mathrm{N}$ & $\mathrm{H}$ & $\mathrm{O}$ \\
\hline 5.0 & 2.0 & 4.0 & 4.0 & 2.0 & 0.07 & 0.01 & 0.01 & 0.001 & 0.12 \\
\hline
\end{tabular}

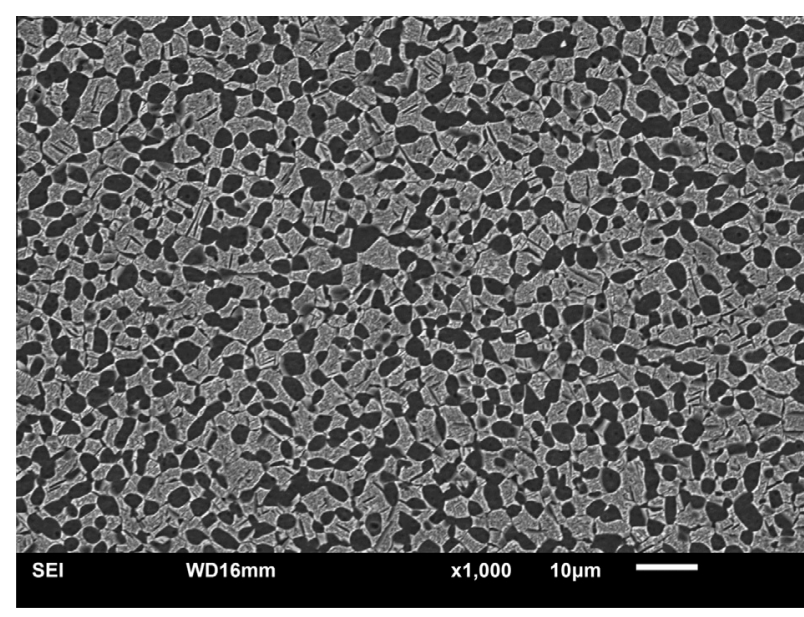

Fig. 1. TC-17 microstructure.

show the difference in fatigue crack initiation site with or without facets. With increase in the number of cycles, the $S-N$ curves at $R>-1$ showed a decreasing trend from $10^{4}$ to $10^{9}$ cycles, however, at $R=-1$, the test results show a horizontal asymptote shape. The effect of the frequency on fatigue life was negligible however, at $R=0.1$, a higher scatter fatigue lives was observed.

In the tests with stress ratio greater than -1 , a constant tensile force was applied to the specimen by the static tensile machine. The elongation of the specimen during the ultrasonic test was measured by a displacement sensor at stress ratio $0.1,0.5$ and 0.7 at $20 \mathrm{kHz}$. In Fig. 3, after a fast increase of the elongation at the beginning, the displacement continued to increase slowly until a sudden growth at the end of the test. Before the final fracture, the rapid increase of the displacement was observed due to the crack propagation. At $10^{7}$ cycles, the displacement increment at the relative stable stages of the VHCF specimen at $R=0.1,0.5,0.7$ with stress amplitude $400,250,170 \mathrm{MPa}$ were $0.12,0.16,0.22 \mathrm{~mm}$ respectively at $10^{7}$ cycles as shown in Fig. 3. This may be attributed to the cyclic creep at room temperature. The ultrasonic fatigue load and tensile mean stress produced the cyclic creep deformation for the steels at room temperature was reported by Kovacs et al. [14]. Ankem et al. [15] showed that the sliding of the interface of alpha/beta grains, grain boundaries and colony boundaries of titanium alloy may show the creep deformation in the cyclic load with mean stress in low temperature.

\subsection{Temperature increasing in fatigue tests}

Infrared camera was used to record the temperature evolutions of the tests at $20 \mathrm{kHz}$. In the same ultrasonic test condition, the temperature increasing reflects the material intrinsic dissipation related with the local irreversible deformation in cyclic load with mean stress. As reported by Ranc [16] for the ultrasonic fatigue tests, after rapid increase in the early temperature evolution stage, the heat balance was formed between the dissipated energy induced by the micro visoplastic deformation and the loss of thermal energy. The average temperature increment values for $R=-1$, $0.1,0.5$ and 0.7 at $10^{7}$ are given in Fig. 4(a) with stress amplitude. At $R=-1$, a bilinear curve for the temperature increasing with an "intersection" point at $460 \mathrm{MPa}$ was observed. The other curves at $R=0.1,0.5$ and 0.7 show the nonlinear temperature evolution. In Fig. 4(b), the temperature increment with stress ratio showed a linear increase at stress amplitude at $150 \mathrm{MPa}$, however, when the stress amplitude reached to $170 \mathrm{MPa}$, the temperature growth enhanced after $R=0.5$. 


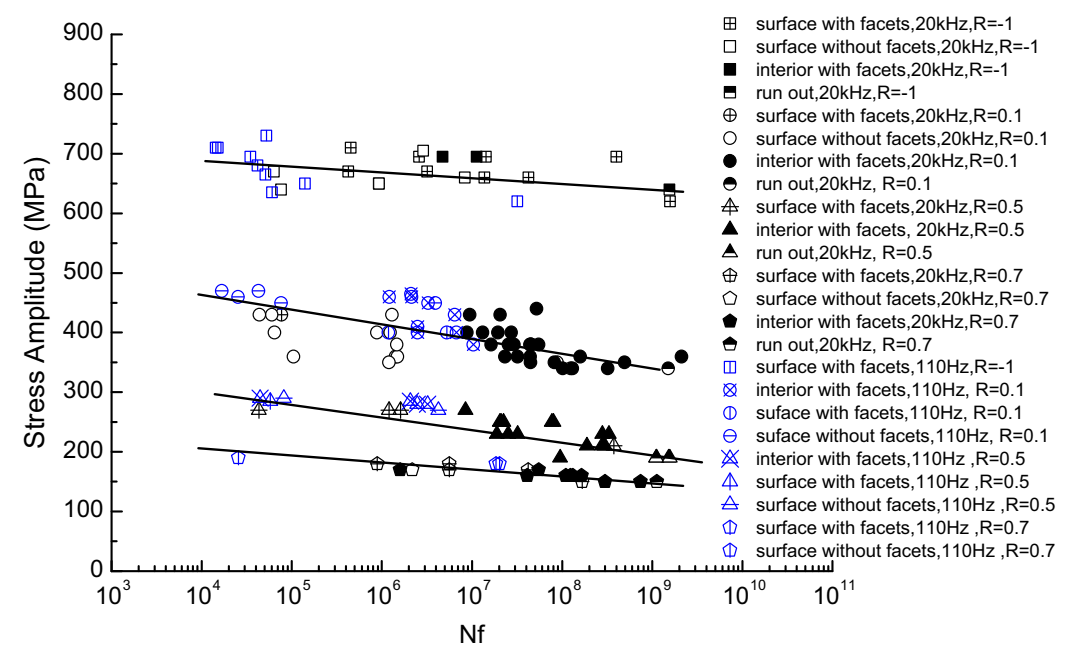

Fig. 2. $S-N$ curves of TC-17 with stress ratios of $-1,0.1,0.5,0.7$ at $110 \mathrm{~Hz}$ and $20 \mathrm{kHz}$ in RT.

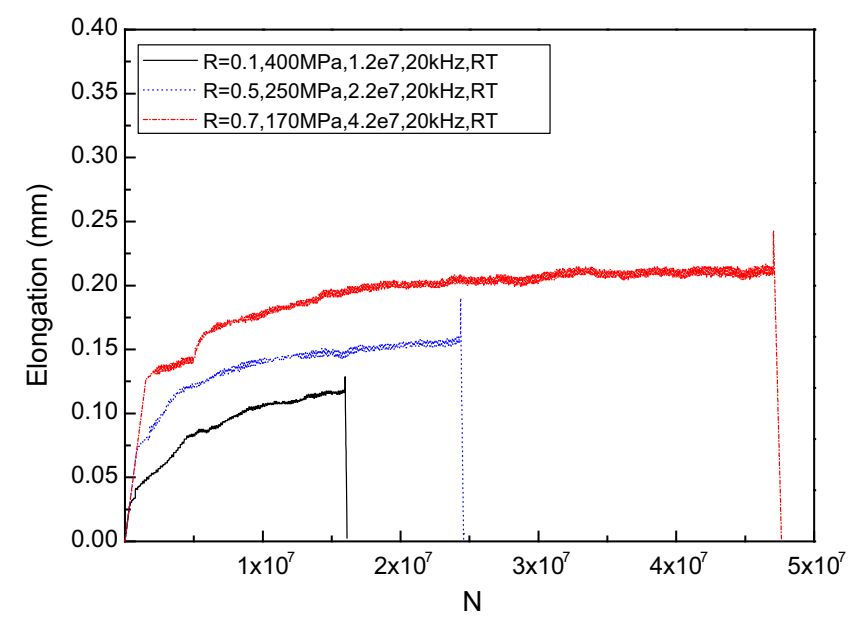

Fig. 3. Elongation of specimen during VHCF $(20 \mathrm{kHz}, \mathrm{RT})$ for $R=0.1,0.5$ and 0.7 .

\section{Fractography}

Some fracture surfaces of the broken specimens were observed by Scanning Electron Microscope (SEM). In HCF/VHCF regime, the crack initiation modes like "surface induced fracture" and "interior inclusion induced fracture" are very common [17]. For the titanium alloy, the interior initiation showed without inclusion as shown in Fig. 5. The morphology of crack initiation zone showed a rough area with many small facets in $20 \mathrm{kHz}$ (Fig. 5) and in $110 \mathrm{~Hz}$ (Fig. 6). Some group of facets or clustered facets were observed (Figs. 5 and 6 ) in the crack initiation zone and several river marks around the initiation zone were observed. Fig. 5 shows white ridges and a "wing" near the initiation site which are considered as the edges of the crack propagation planes.

The high magnification image of the initiation regime shows the diameter of the facets were about $4-5 \mu \mathrm{m}$, similar to the average size of the grains (Figs. 5 and 6). In terms of the report [18], the flat facets are identified as the cleavage fracture of the $\alpha_{\mathrm{p}}$ grains. As shown in Fig. 7, some grains at $R=0.5$ showed brittle transgranulare fracture.

From the fracture morphology analysis, as suggested by Liu et al. [18], the crack initiation was characterized in three categories: "surface initiation", "surface initiation with facets" and "interior initiation with facets". The occurrence probability of
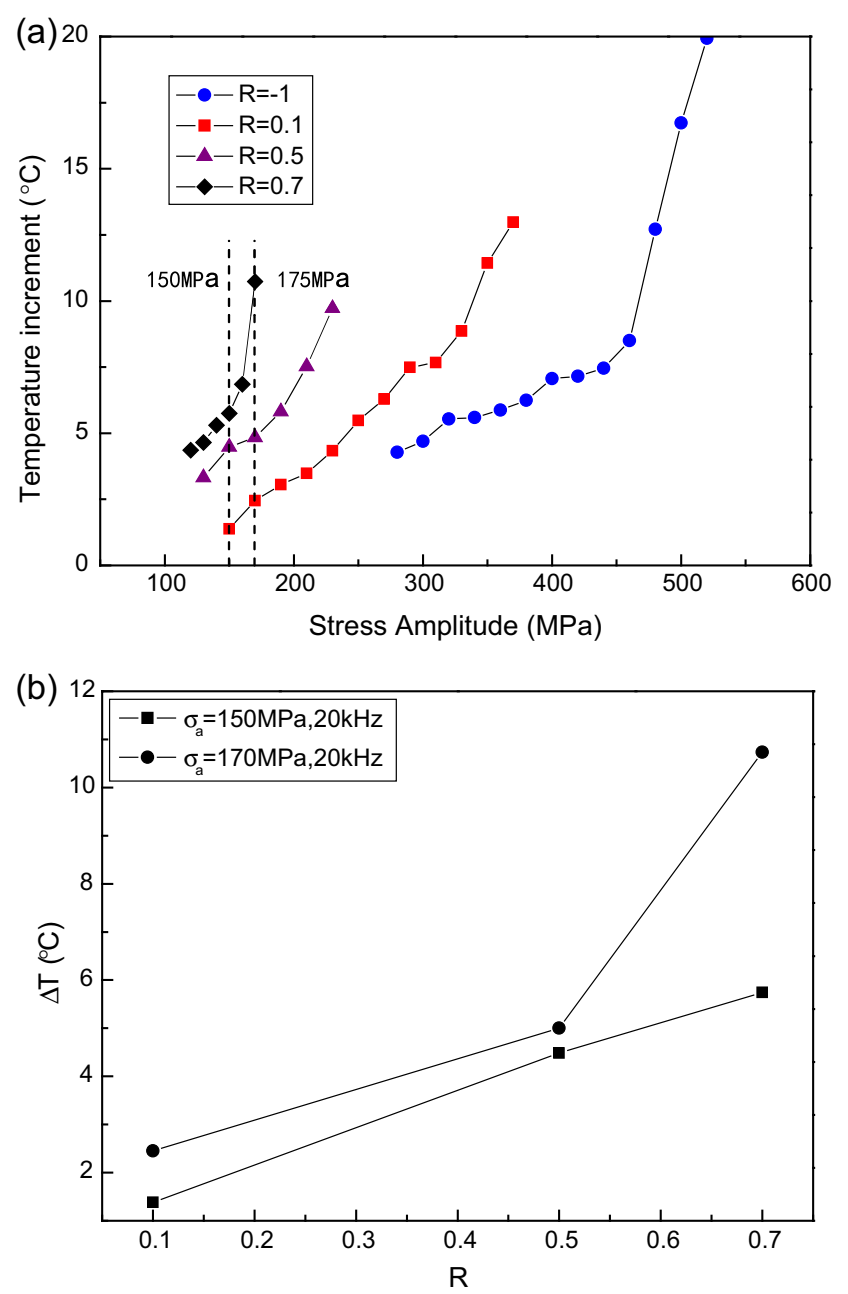

Fig. 4. Temperature increment versus stress amplitude (a) and temperature increment versus stress ratio at $150 \mathrm{MPa}$ and $170 \mathrm{MPa}$ stress amplitude (20 kHz, RT) (b).

facets in the fracture specimens is plotted in Fig. 8a for $110 \mathrm{~Hz}$ and Fig. $8 \mathrm{~b}$ for $20 \mathrm{kHz}$ respectively which show similar trend in the two test frequencies. With the stress ratio increasing, the probability of the small facets initiated from subsurface was enhanced 


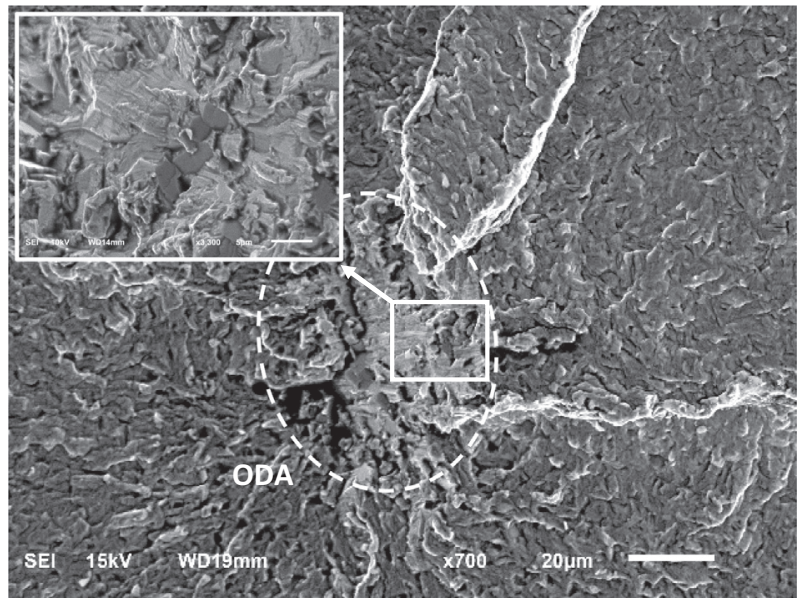

Fig. 5. Interior crack initiation of the specimen with facets at $R=0.1,20 \mathrm{kHz}$ $\left(\sigma_{\mathrm{a}}=430 \mathrm{MPa}, \mathrm{Nf}=9.416 \mathrm{E}+6\right)$.

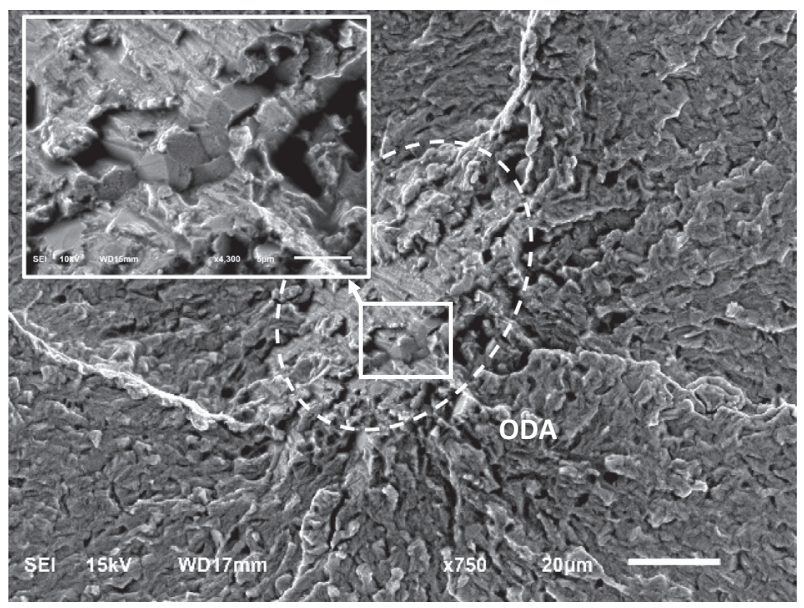

Fig. 6. Interior crack initiation with facets at $R=0.5$ and $110 \mathrm{~Hz}\left(\sigma_{\mathrm{a}}=270 \mathrm{MPa}\right.$ $\mathrm{Nf}=4.2536 \mathrm{E} 6)$.

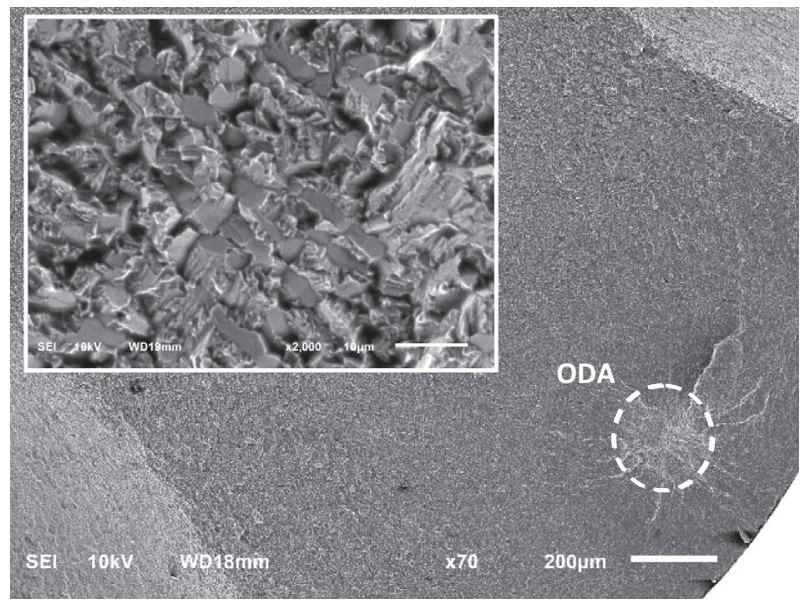

Fig. 7. Interior crack initiation and the facets in the center of the "ODA" at $R=0.5$, $20 \mathrm{kHz}\left(\sigma_{\mathrm{a}}=250 \mathrm{MPa}, \mathrm{Nf}=2.036 \mathrm{E} 7\right)$.

from $R=-1$ to 0.5 . The interior crack initiation proportion with facets reached the maximum value at $R=0.5$, and the surface induced crack with facets attained lowest percentage value at $R=0.1$ and highest at $R=0.7$ both for $110 \mathrm{~Hz}$ and $20 \mathrm{kHz}$ tests.
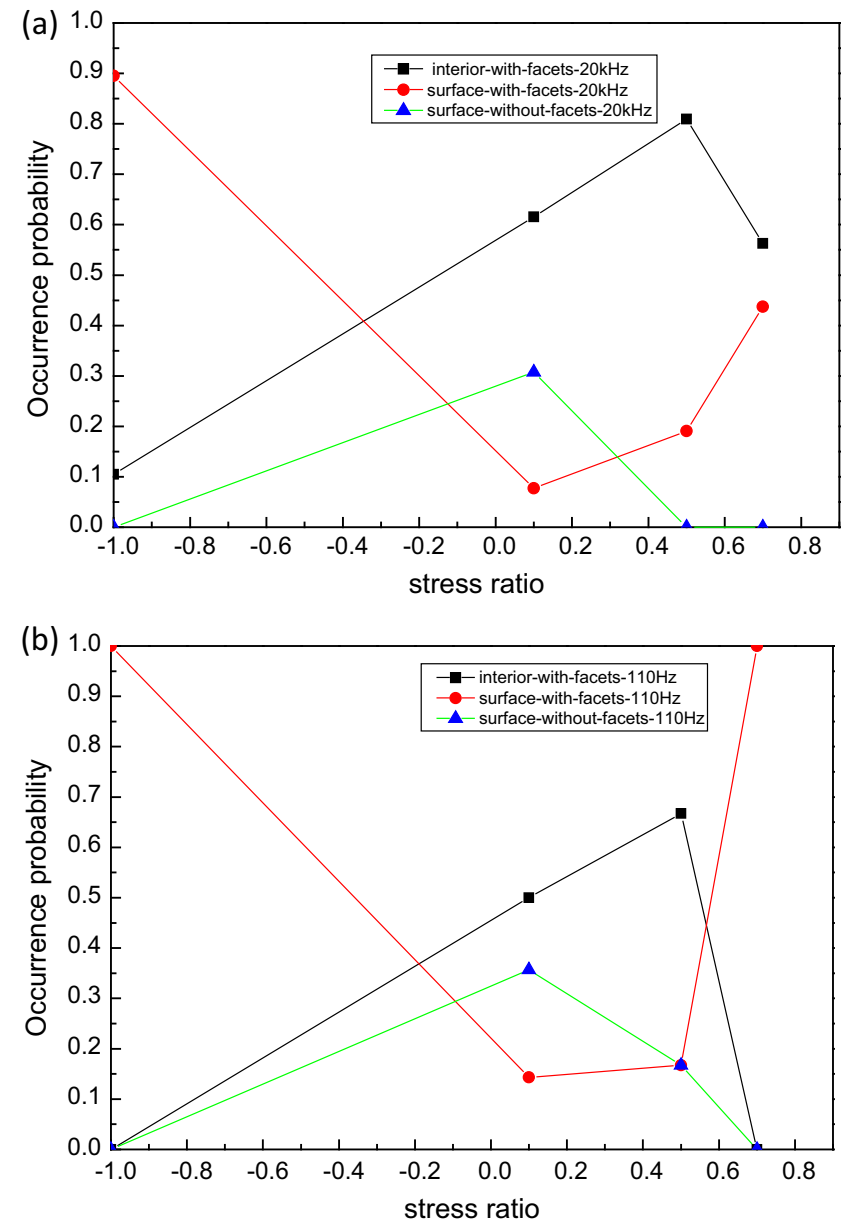

Fig. 8. Occurrence probability of crack initiation from interior and surface with or without facets in $20 \mathrm{kHz}$ (a) and in $110 \mathrm{~Hz}$ (b).

The mean stress grows the maximum stress and gives rise to the high occurrence probability of the facets in the interior and surface initiation fractures at $110 \mathrm{~Hz}$ and $20 \mathrm{kHz}$.

\section{Discussions}

\subsection{Frequency effect on VHCF fatigue}

Endurance test results of the TC-17 alloy on ultrasonic machine $(20 \mathrm{kHz})$ and electromagnetic machine $(110 \mathrm{~Hz})$ showed no effect of cyclic frequency on lifetimes at $R=-1,0.1,0.5$ and 0.7 (Fig. 2). In VHCF regime, the local micro-inelastic deformation caused by irreversible dislocation slips may still occur in some regions and accumulate the damage to create micro- crack and induce the final failure [19]. Mughrabi et al. [20] showed the local flow stress in fatigue for metals was variable with strain rates. It was assumed that the fatigue properties were combined effect of temperature and strain rate which could influence the flow stress. In terms of the work of Papakyriacou et al. [21], the effect of loading frequency of titanium alloy with H.C.P structure on the flow stress was very little as a consequence of planar slips. For the TC-17 alloy, the local flow stress seems was not affected by the loading frequency due to the H.C.P planar slips of the primary alpha grains. The fatigue strength in $20 \mathrm{kHz}$ was not increased at $10^{7}$ cycles as compared to $110 \mathrm{~Hz}$ (Fig. 2).

The higher cyclic frequency can generate more heat in a fixed time interval. Part of irreversible deformation energy from the 
damaged grains is transferred into heat and increases the surface temperature. In fatigue tests, the heat dissipated by thermal conduction was dependent on the microscopic plastic deformation of the excited grains [16], the cyclic frequency and the boundary conditions of the heat transfer. The maximum temperature increment in the $20 \mathrm{kHz}$ tests was about $10-20^{\circ} \mathrm{C}$ of the alloy which was not enough to affect the mechanical properties significantly.

\subsection{Stress ratio effect on fatigue crack initiation}

For the subsurface crack initiation, the fracture surface presents a clear crack initiation zone "ODA" as shown in Figs. 5-7. The morphology of "ODA" was different with the other regions. The roughness of the "ODA" was higher than the rest part of the "fish eye" zone. Stanzl-Tschegg et al. [22] proposed that the lower stresses damage the material and cause the irreversible deformation which develops slip bands on the surface or around the interior defects of the specimen. When the facets appear in the initiation zone, the fracture mechanism was controlled by the facets formation both in HCF and VHCF irrespective of loading frequency. The $\alpha$ phase grain of titanium alloy with H.C.P microstructure provides slips systems like $\langle a\rangle$ slips on basal, prismatic and pyramidal planes, and $\langle c+a\rangle$ direction on pyramid planes [23]. The basal and prismatic slip system have lowest critical resolved shear stress (CRSS) [24]. The enlarged image of the center of initiation zone shows many facets (Fig. 8b) showing cleavage fracture of the $\alpha$ grains in the high Schmid factor slip planes. The accumulated irreversible slips in low stress fatigue damage some grains and cause the cleavage micro crack in the $\alpha_{\mathrm{p}}$ grains. The following micro crack nucleation process for the broken grains form an initiation area with rough surface under the interaction of the $\beta$ and the $\alpha$ grains with increase in the fatigue cycles.

In Fig. 9, several facets of the $\alpha_{\mathrm{p}}$ grain with slip traces are found (shown by the white arrows) which also exist in the enlarged photos of Figs. 6 and 7, indicating the major irreversible localized deformation. In another study [25], TEM images show that the crack initiation was due to the irreversible slips and pile ups dislocations on basal plane. It was observed that the facet plane was inclined to the basal plane in the HCF and VHCF regime. Some facets along the prismatic planes were also observed [24] and showed that the prismatic and basal Schmid factor can induce the gliding at 0.48 . The first order pyramidal gliding occurred at a higher value: 0.49 and the basal and prismatic slips showed a higher occurrence probability.

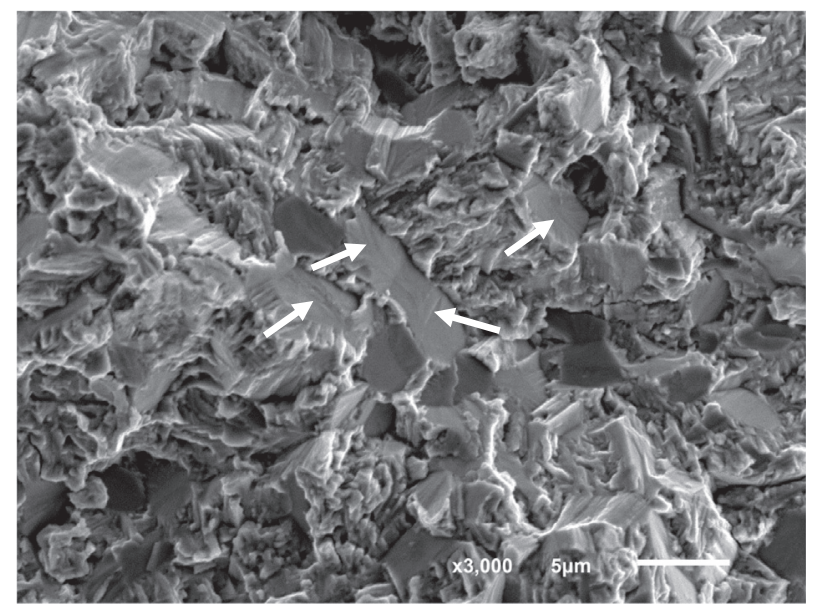

Fig. 9. Slip traces in the crack initiation zone at $R=0.7,20 \mathrm{kHz}, \sigma_{\mathrm{a}}=150 \mathrm{MPa}$, $\mathrm{Nf}=2.99 \mathrm{e} 8$ ).
The crack along the slip plane was easy to form the facets in combination of high Schmid factor and tensile stresses normal to the slip plane $[23,26]$. Fig. 10 shows that more facets were found in the higher stress ratio at $110 \mathrm{~Hz}$ and $20 \mathrm{kHz}$. The performance of titanium alloys often appears the cyclic creep in low temperature $(<0.25$ melt temperature) including room temperature as reported by Neeraj et al. [27]. The creep deformation occured in the operative planar slip on both prismatic and basal planes in alpha grains observed by TEM [27] and the interaction between different slip systems were low for the Ti-6Al titanium alloy. The mean stress at high stress ratio enhanced the planar slips with local cyclic creep deformation which increased the occurrence of the crack initiation with the facets.

\subsection{Effect of mean stress on fatigue strength}

With the help of ultrasonic fatigue test machine, the overall fracture behavior of the effect of the material was obtained when loaded at different means stresses in VHCF. In order to understand the effect of mean stress on the fatigue strength, stress amplitudes at $10^{9}$ with $50 \%$ failure probability were plotted in Fig. 11 with stress ratios. The stress ratios affect the slopes of the $S-N$ curves in Fig. 2. The slopes at $R=0.1$ and 0.5 are higher than $R=-1$ and 0.7 . The higher occurrence probability of the crack initiation from the interior with facets at $R=0.1,0.5$ could weaken the fatigue strength and change the $S-N$ curves' slopes in VHCF. TC- 17 alloy was inclined to internal fracture at $R=0.5$, but at $R=0.7$, the internal fracture occurrence declined both in $110 \mathrm{~Hz}$ and $20 \mathrm{kHz}$ (Fig. 8).

With the increase of the number of cycles $\left(>10^{7}\right)$, the VHCF fracture below the "fatigue limit" occurred at $R>=-1$ [28]. Sakai found that the fatigue limit tends to decrease almost proportionally with the increase of the mean stress in the range of $-1<R<0.5$. He proposed a bilinear model at $N=10^{8}$ with an intersect point at $R=0.5$ [29]. The fatigue strengths at $R=0.1,0.5$ and 0.7 were lower than the modified Goodman line. The bilinear model proposed by Sakai showed good agreement for the VHCF fatigue strength at $10^{9}$ cycles as shown in Fig. 11. As reported by Furuya et al. [30] for Ti-6Al-4V alloy, the similar fatigue strength behavior in VHCF was found. The modified Goodman line normally shows conservative results with high safety margin. However, in VHCF, the stress amplitude go through the safety line to the dangerous side. The lower fatigue strength with stress ratio variation in VHCF can be termed as a very complicated phenomenon. The more facets formation in the crack initiation zone in low macroscopic stress amplitude with means stress affected the fatigue strength of the alloy substantially in

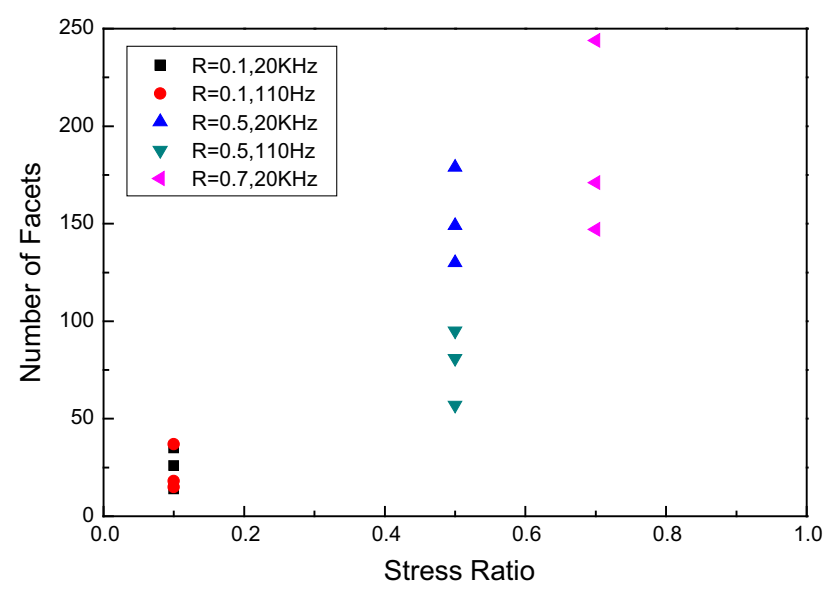

Fig. 10. Number of facets increasing with stress ratio in the crack initiations zone for the specimens tested in $110 \mathrm{~Hz}$ and $20 \mathrm{kHz}$, RT. 


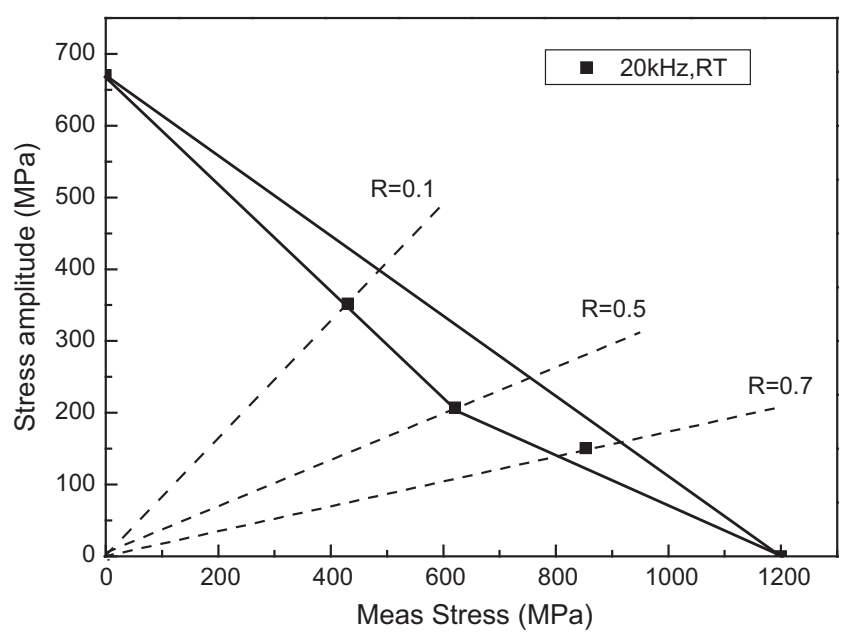

Fig. 11. Fatigue strength at $10^{9}$ cycles diagram with mean stress at $20 \mathrm{kHz}$, RT.

the VHCF regime. The mean stress enhanced the micro accumulated irreversible inhomogeneous deformation of the grains due to planar slips in HCF and VHCF regimes.

\section{Conclusions}

The article investigates the effect of stress ratio on the fatigue strength in HCF/VHCF regime in two fatigue test frequencies $(110 \mathrm{~Hz}$ and $20 \mathrm{kHz})$ by experimental methods at $R=-1,0.1,0.5$ and 0.7 in room temperature. The main conclusions obtained are summarized as follows:

1. The surface and interior crack initiation are induced with facets irrespective of the test frequencies.

2. The effect of frequency on fatigue strength for TC-17 alloy produced no difference on the lifetimes.

3. The facets in the initiation zone is the cleavage fracture was produced due to the operative slip on basal or prismatic planes of the grains with high Schmid factor. The enhanced planar slip and the local cyclic creep strain with mean stress increased the growth of the $\alpha_{\mathrm{p}}$ grain facets.

4. The fatigue strengths at $R=0.1,0.5$ and 0.7 were found to be lower than the modified Goodman line when the facets numbers increased in crack initiation. The facets formation in the crack initiation zone in low macroscopic stress amplitude with means stress decreased the fatigue strength of the alloy in VHCF.

\section{Acknowledgment}

Financial support by National Natural Science Research Foundation of China (No. 11372201) is gratefully acknowledged.

\section{References}

[1] Shanyavskiy AA. Fatigue limit - material property as an opened or closed system? Practical view on the aircraft components failures in GCF area. Int J Fatigue 2006;28. 1647-7.

[2] Nicholas T. Critical issues in high cycle fatigue. Int J Fatigue 1999;21:S221-31.

[3] Bathias C, Paris PC. Gigacycle fatigue in mechanical practice. New York: Marcel Dekker; 2005.
[4] Bathias Claude. Piezoelectric fatigue testing machines and devices. Int J Fatigue 2006;28(11):1438-45.

[5] Marines I, Dominguez G, Baudry G, Vittori J-F, Rathery S, Doucet J-P, et al. Ultrasonic fatigue tests on bearing steel AISI-SAE 52100 at frequency of 20 and 30 kHz. Int J Fatigue 2003;25(9-11):1037-46.

[6] Stanzl S. New experimental method for measuring life time and crack growth of materials under multi-stage and random loadings. Ultrasonics 1981 (November):269-72.

[7] Marines-Garcia Israel, Doucet Jean-Pierre, Bathias Claude. Development of a new device to perform torsional ultrasonic fatigue testing. Int $\mathrm{J}$ Fatigue 2007;29(9-11):2094-101. ISSN 0142-1123.

[8] Mayer $H$. Ultrasonic torsion and tension-compression fatigue testing: measuring principles and investigations on 2024-T351 aluminium alloy. Int J Fatigue 2006;28(11):1446-55. ISSN 0142-1123.

[9] Xue HQ, Tao H, Montembault F, Wang QY, Bathias C. Development of a threepoint bending fatigue testing methodology at $20 \mathrm{kHz}$ frequency. Int J Fatigue 2007;29(9-11):2085-93.

[10] Filgueiras Pedro F, Bathias Claude, Palma Ernani S, Wang Chong. Inducing very high cycle fretting-fatigue in the ultrasonic regime. Tribol Int 2014;76 (August):57-62. ISSN 0301-679X.

[11] Zimmermann M, Stöcker C, Christ H-J. On the effects of particle strengthening and temperature on the VHCF behavior at high frequency. Int J Fatigue 2011;33(1):42-8. ISSN 0142-1123.

[12] Pérez-Mora Ruben, Palin-Luc Thierry, Bathias Claude, Paris Paul C. Very high cycle fatigue of a high strength steel under sea water corrosion: a strong corrosion and mechanical damage coupling. Int J Fatigue 2015;74 (May):156-65. ISSN 0142-1123.

[13] Stöcker Christian, Zimmermann Martina, Christ Hans-Jürgen. Effect of precipitation condition, prestrain and temperature on the fatigue behaviour of wrought nickel-based superalloys in the VHCF range. Acta Mater 2011;59 (13):5288-304.

[14] Kovacs S, Beck T, Singheiser L. Influence of mean stresses on fatigue life and damage of a turbine blade steel in the VHCF-regime. Int J Fatigue 2013;49 (April):90-9.

[15] Ankem Sreeramamurthy, Margolin Harold, Greene Charles A, Neuberger Brett W, Oberson P Gregory. Mechanical properties of alloys consisting of two ductile phases. Prog Mater Sci 2006;51:632-709.

[16] Ranc N, Wagner D, Paris PC. Study of thermal effects associated with crack propagation during very high cycle fatigue tests. Acta Mater 2008;56 (15):4012-21.

[17] Sakai T, Sato Y, Oguma N. Characteristic SN properties of high-carbonchromium-bearing steel under axial loading in long-life fatigue. Fatigue Fract Eng Mater Struct 2002;25(8-9):765-73.

[18] Liu Xiaolong, Sun Chengqi, Hong Youshi. Effects of stress ratio on high-cycle and very-high-cycle fatigue behavior of a Ti-6Al-4V alloy. Mater Sci Eng, A 2015;622:228-35.

[19] Zhao Aiguo, Xie Jijia, Sun Chengqi, Lei Zhengqiang, Hong Youshi. Effects of strength level and loading frequency on very-high-cycle fatigue behavior for a bearing steel. Int J Fatigue 2012;38(May):46-56.

[20] Mughrabi H, Herz K, Stark X. Int J Fract 1981;17:193-220.

[21] Papakyriacou M, Mayer H, Pypen C, Plenk Jr H, Stanzl-Tschegg S. Influence of loading frequency on high cycle fatigue properties of b.c.c. and h.c.p. metals. Mater Sci Eng 2001;A308:143-52.

[22] Stanzl-Tschegg S, Mughrabi H, Schoenbauer B. Life time and cyclic slip of copper in the VHCF regime. Int J Fatigue 2007;29:2050-9.

[23] Jha Sushant K, Szczepanski Christopher J, John Reji, Larsen James M. Deformation heterogeneities and their role in life-limiting fatigue failures in a two-phase titanium alloy. Acta Mater 2015;82:378-95.

[24] Bridier F, Villechaise P, Mendez J. Slip and fatigue crack formation processes in an $\alpha / \beta$ titanium alloy in relation to crystallographic texture on different scales. Acta Mater 2008;56:3951-62.

[25] Baxter GJ, Rainforth WM, Grabowski L. TEM observations of fatigue damage accumulation at the surface of the near- $\alpha$ titanium alloy IMI 834. Acta Mater 1996;44(9):3453-63.

[26] Szczepanski CJ, Jha SK, Larsen JM, Jones JW. Microstructural influences on very-high-cycle fatigue-crack initiation in Ti-6246. Metall Mater Trans A 2008;39A(December):2841.

[27] Neeraj T, Hou D-H, Daehn GS, Mills MJ. Phenomenological and microstructural analysis of room temperature creep in titanium alloys. Acta Mater 2000;48:1225-38.

[28] Sakai T, Lian B, Takeda M, Shiozawa K, Oguma N, Ochi Y, et al. Statistical duplex $S-N$ characteristics of high carbon chromium bearing steel in rotating bending in very high cycle regime. Int J Fatigue 2010;32:497-504.

[29] Sakai T, Sato Y, Nagano Y, Takeda M, Oguma N. Effect of stress ratio on long life fatigue behavior of high carbon chromium bearing steel under axial loading. Int J Fatigue 2006;28:1547-54.

[30] Furuya Yoshiyuki, Takeuchi Etsuo. Gigacycle fatigue properties of Ti-6Al-4V alloy under tensile, mean stress. Mater Sci Eng A 2014;598:135-40. 